\title{
Metabolic response to cold in the newborn
}

\author{
O. R. C. SMALES AND D. HULL \\ From the Department of Child Health, University Hospital and Medical School, Nottingham
}

SUMMARY Blood concentrations of glycerol and free fatty acids were measured in healthy and sick 5-day-old infants during and after cold exposure. In apparently similar infants in similar circumstances, the blood concentrations varied widely. Although the concentrations of both glycerol and free fatty acids tended to be higher during cold exposure, it is not possible to use either as an index of cold exposure in individual infants.

One of the objectives of intensive care of the newborn is to maintain an ambience which reduces the environmental stresses, and hence the challenge to the infant's homoeostatic responses, to a minimum. Cold presents a considerable challenge to the newborn infant and a number of clinical studies have shown the particular vulnerability of the sick preterm infant to cold environments (Hey, 1971). Unfortunately, it is just such infants who give very little indication that they are experiencing hot or cold and, if they are, whether or not they are responding to it.

In experimental studies on newborn animals, cold exposure has been shown to produce a predictable rise in metabolic rate and in the circulating concentrations of glucose and the products of lipolysis, glycerol, and free fatty acids (FFA) (Hardman and Hull, 1969; Alexander et al., 1972). Experimental studies on healthy preterm and mature newborn infants have shown that they too have predictable thermoregulatory responses to cold. From these studies recommendations have been made on the environment required to provide comfortable temperatures (ones which do not stimulate thermoregulatory adjustments) for infants of varying size, gestation, and postnatal age (Hey, 1969). The use of a simple open-circuit system to study $\dot{\mathrm{V}}_{2}$ in infants in the nursery confirms that those measurements made under precise environmental conditions are a valuable guide, but they could be quite misleading for individual infants, particularly sick infants (Smales, 1978).

Also in newborn infants, many studies have been made on the circulating concentrations of glucose, glycerol, and FFA, and the changes which occur in response to cold exposure (Persson and Gentz, 1966; Melichar and Wolf, 1967; Dawkins and Scopes, 1965;

Received 24 October 1977
Př̀ibylová and Novak, 1970; Gentz et al., 1976). Again they are consistent with the animal studies in showing that cold provokes an increase in all three concentrations in newborn man as in animals. As blood samples are frequently taken from sick newborn infants, and as FFA and glycerol concentrations have been shown to increase with cold exposure, and as their concentration can now be measured on very small volumes of blood, the possibility that their concentrations might be used as an index of an individual infant's response to cold exposure was explored.

\section{Methods}

This study was performed on the fifth day when blood was being routinely taken for Guthrie test. 10 babies were in the department of neonatal medicine for various problems (Table) (called 'abnormal group'). Their mean ( \pm SD) birthweight was $2 \cdot 28 \pm 0 \cdot 30 \mathrm{~kg}$, and gestation was $35 \cdot 7 \pm 1 \cdot 1$ weeks. 10 were in the lying-in nurseries and had a mean birthweight of $3.02 \pm 0.27 \mathrm{~kg}$, and gestation

\section{Table Clinical details of 10 infants in the 'abnormal} group'

\begin{tabular}{|c|c|c|c|}
\hline $\begin{array}{l}\text { Case } \\
\text { no. }\end{array}$ & $\begin{array}{l}\text { Gestation } \\
(w)\end{array}$ & $\begin{array}{l}\text { Birth- } \\
\text { weight } \\
(\mathrm{kg})\end{array}$ & Clinical features \\
\hline 1 & 33 & $1 \cdot 30$ & Twin; jaundiced; light-for-dates \\
\hline 2 & 36 & $1 \cdot 76$ & Twin; light-for-dates \\
\hline 3 & 35 & $1 \cdot 95$ & Twin; birth asphyxia \\
\hline 4 & 40 & $3 \cdot 34$ & Transient tachypnoea; jaundice \\
\hline 5 & 35 & $2 \cdot 34$ & $\begin{array}{l}\text { Rh haemolytic disease; } 3 \text { exchange } \\
\text { transfusions }\end{array}$ \\
\hline 6 & 35 & $2 \cdot 02$ & Mild RDS; jaundice \\
\hline 7 & 39 & $4 \cdot 30$ & Birth asphyxia; jaundice \\
\hline 8 & 40 & $2 \cdot 71$ & Fetal distress; forceps delivery \\
\hline 9 & 36 & $1 \cdot 99$ & $\begin{array}{l}\text { Light-for-dates; birth asphyxia; } \\
\text { convulsions }\end{array}$ \\
\hline 10 & 28 & $1 \cdot 10$ & Apnoea of prematurity; jaundice \\
\hline
\end{tabular}


of $38.4 \pm 0.08$ weeks ('normal group'). Permission for the study was obtained from the parents after they had been given a full explanation of what the investigation involved.

All the studies were performed one hour after each feed. The rate of $\mathrm{O}_{2}$ consumption was measured via a face mask using a simple open-circuit technique (Smales, 1978). The infant's rate of $\mathrm{O}_{2}$ consumption was first measured after 20 minutes exposure at an ambient temperature which was $6^{\circ} \mathrm{C}$ below the lower critical temperature as predicted from age and weight from the values reported by Hey (1971). The infants were then placed at the predicted thermoneutral temperature for one hour and their $\mathrm{O}_{2}$ consumption and deep body temperature measured again. Blood samples were collected after each period and analysed for glucose by the method of Huggett and Nixon (1957), for FFA by the automatic method of Elphick (1975), and for glycerol using the Boehringer Kit.

\section{Results}

After 20 minutes at $6^{\circ} \mathrm{C}$ below the thermoneutral temperature there was no significant difference in the mean rate of $\mathrm{O}_{2}$ consumption between the normal and abnormal babies and when transferred to a thermoneutral environment the fall in $\mathrm{O}_{2}$ consumption was similar (Fig. 1). In normal babies rectal temperature was not significantly influenced by the
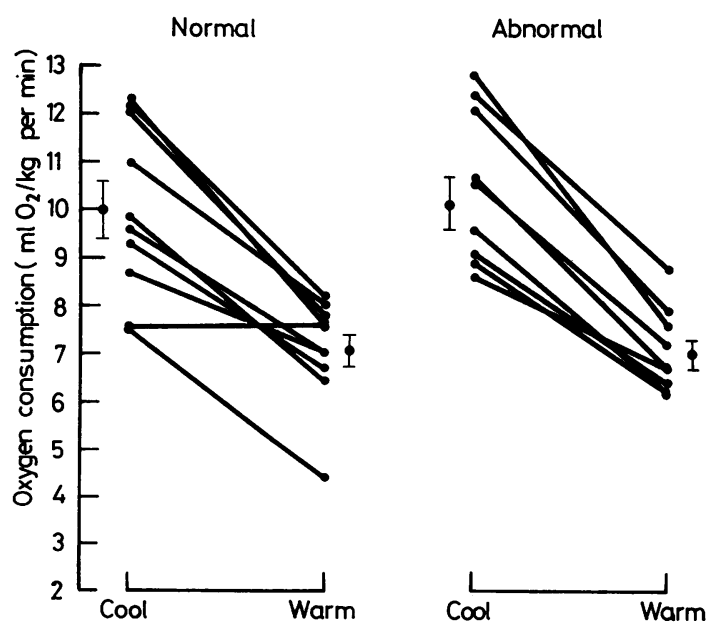

Fig. 1 Rates of $\mathrm{O}_{2}$ consumption of two groups of infants. Measurements were first made in a cool environment calculated to be $6{ }^{\circ} \mathrm{C}$ below the neutral range on the basis of the information provided by Hey (1971) and then again after the babies had been for an hour in a warm environment. In this and subsequent figures, - represents the mean, and the vertical line $\pm 1 S E$ of the mean. alterations in environmental temperature. However, the mean rectal temperature of the abnormal group was lower after cooling than after an hour at a thermoneutral temperature $(\mathrm{P}<0.02)$ (Fig. 2).

Plasma glucose levels were not found to alter significantly when the environmental temperature was altered and there was no significant difference between the two groups (Fig. 3). Plasma glycerol levels were higher in normal babies exposed to cold than after an hour at a thermoneurtal temperature
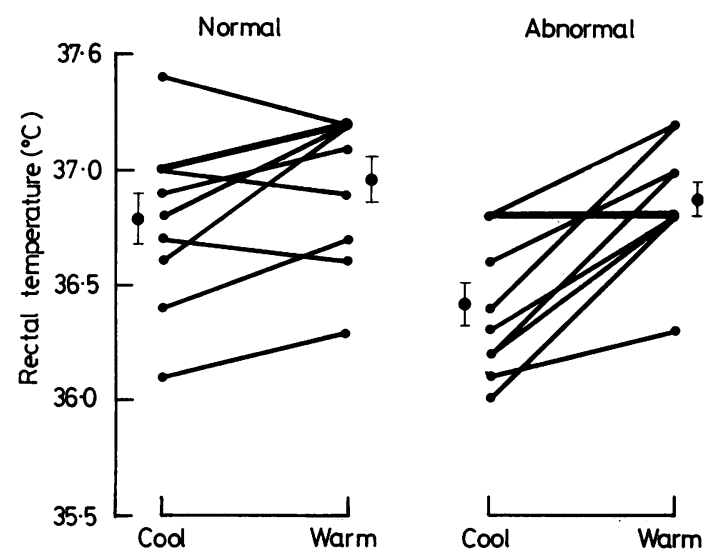

Fig. 2 Rectal temperatures of the two groups of infants whose $\mathrm{O}_{2}$ consumptions are shown in Fig. 1. The healthy but small infants in the 'abnormal' group had on average a significantly larger fall in rectal te riperatures.
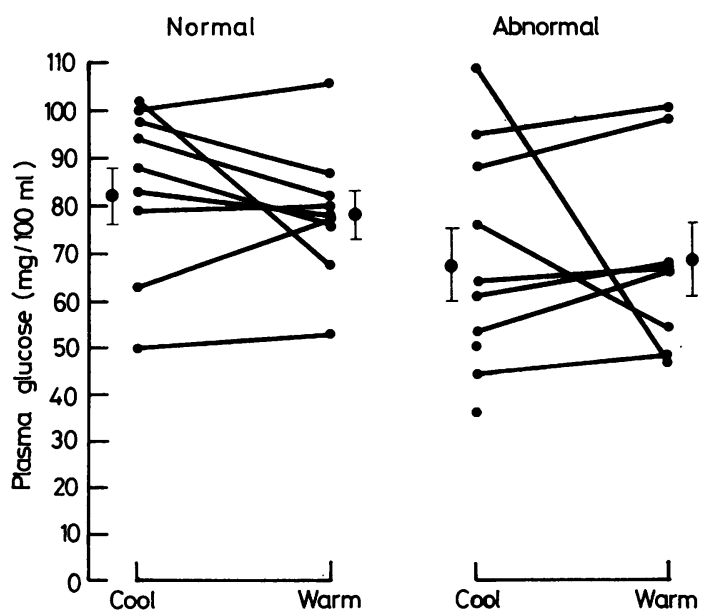

Fig. 3 Plasma glucose concentrations in the two groups of infants studied at the two environmental temperatures. Conversion: Traditional units to SIGlucose: $1 \mathrm{mg} / 100 \mathrm{ml} \approx_{\mathrm{s}}^{\mathrm{r}} 0.0555 \mathrm{mmol} / \mathrm{l}$. 
$(\mathrm{P}<0.02$, paired ' $\mathrm{t}$ ' test). This did not occur in the abnormal group (Fig. 4). FFA levels did not alter in a consistent manner with the alteration in environmental temperature, but the wide range of values found in the abnormal group was a striking feature (Fig. 5).

\section{Discussion}

In previous studies of this nature it has been customary to discuss the trends as shown by changes in the average between groups. In the healthy 5-dayold infants a decrease in the metabolic rate occurred when the infants were transferred from the cool to the warm environment and this was accompanied by a decrease in plasma glycerol concentrations. These findings support the original observation of Dawkins and Scopes in 1965. A similar change in the mean values for the sick infants was also seen with respect to the rate of $\mathrm{O}_{2}$ consumption, but did not occur in the glycerol concentrations. Although there was a trend in the healthy infants for the FFA and glucose concentrations also to fall, neither reached statistical significance.

These trends in mean values are in line with the observations on experimental animals when cold exposure led to a rise in all three metabolites. However, even in the healthy infants there was striking variation from one infant to another, for example the resting metabolic rate varied from

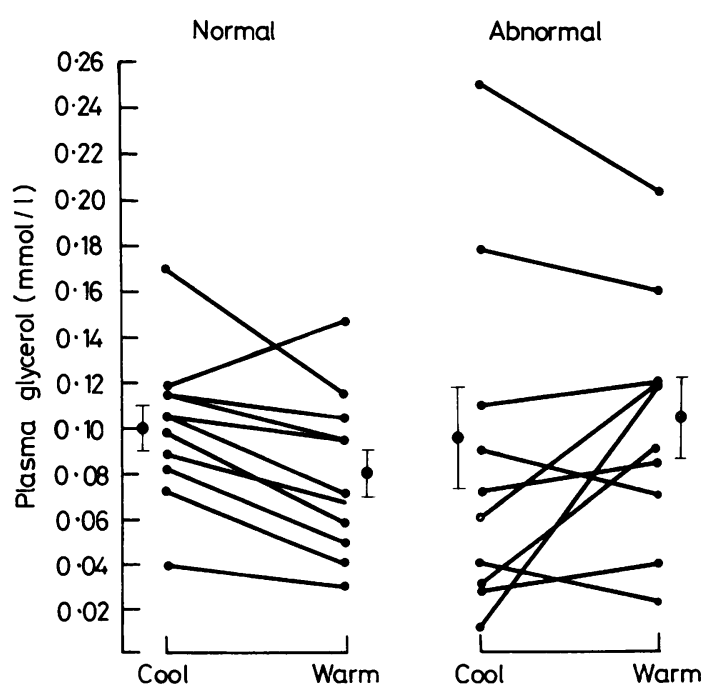

Fig. 4 Plasma glycerol concentrations in the two groups of infants studied at the two environmental temperatures. Conversion: SI to traditional unitsGlycerol : $1 \mathrm{mmol}^{\prime} \mathrm{l} \approx 9.2 \mathrm{mg} / 100 \mathrm{ml}$.
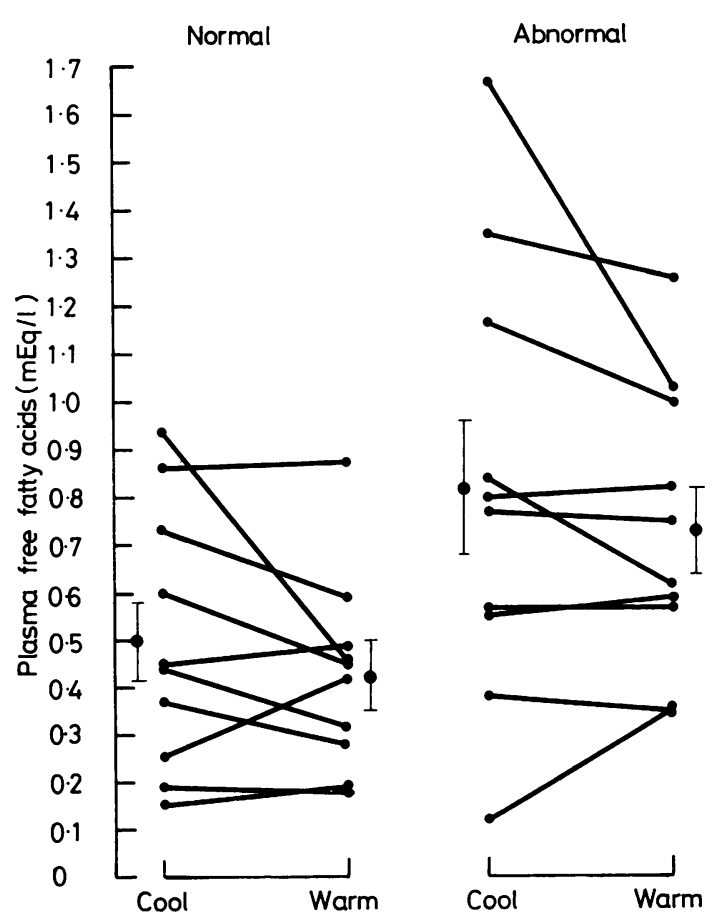

Fig. 5 Plasma free fatty acid concentrations in the two groups of infants studied at the two environmental temperatures.

4.5 to $8 \cdot 2 \mathrm{ml} \mathrm{O}_{2} / \mathrm{kg}$ per min. The FFA concentrations varied from $0 \cdot 18$ to $0 \cdot 88 \mathrm{mEq} / \mathrm{l}$. Animal studies suggest that both the plane of nutrition and previous experience of cold exposure will vary the infant's response, but it is perhaps surprising that there is such wide variation in apparently thriving, healthy, term infants. It is certainly of a magnitude to obscure the comparatively small influences of the ambient temperature.

What is true of the healthy infants is even more apparent in the infants nursed in the special care areas, where a similar variation in metabolic rate was noted and there was a much greater variation in the concentration of glycerol and FFA. From these data it could be argued that it is as important to investigate the factors which influence the infant's minimal metabolic rate and circulating concentrations of FFA as it is to determine whether or not the infant is experiencing a cool environment. It is not, of course, self-evident that it is desirable for the infant never to experience cold exposure, or to have a low metabolic rate.

The results are consistent with previous observations that cold exposure stimulated an increase in 
the infant's rate of $\mathrm{O}_{2}$ consumption and mobilisation of energy reserves. However, circulating concentrations of FFA and glycerol cannot be used as a guide to the infant's level of responsiveness.

\section{References}

Alexander, G., Bell, A. W., and Hales, J. R. S. (1972). The effect of cold exposure on the plasma levels of glucose, lactate, free fatty acids and glycerol and on the blood gas and acid-base status of young lambs. Biology of the Neonate, 20, 9-21.

Dawkins, M. J. R., and Scopes, J. W. (1965). Non-shivering thermogenesis and brown adipose tissue in the human newborn infant. Nature, 206, 201-202.

Elphick, M. C. (1975). Automated modification of Duncombe's method for the ultra-micro determination of serum free fatty acids. Journal of Lipid Research, 16, 402-406.

Gentz, J., Kellum, M., and Persson, B. (1976). The effect of feeding on oxygen consumption, $R Q$, and plasma levels of glucose, FFA, and D- $\beta$-hydroxybutyrate in newborn infants of diabetic mothers and small for gestational age infants. Acta Paediatrica Scandinavica, 65, 445-454.

Hardman, M. J. R., and Hull, D. (1969). The effects of age and environmental temperature on the blood concentrations of glucose, free fatty acids, and glycerol in newborn rabbits. Journal of Physiology, 201, 685-694.
Hey, E. N. (1969). The relation between environmental temperature and oxygen consumption in the new-born baby. Journal of Physiology, 200, 589-603.

Hey, E. N. (1971). The care of babies in incubators, Recent Advances in Paediatrics, pp. 171-216. Ed. by D. Gairdner and D. Hull. Churchill, London.

Huggett, A. St. G., and Nixon, D. A. (1957). Use of glucose oxidase, peroxidase and o-dianisidine in determining blood and urinary glucose. Lancet, 2, 368-370.

Melichar, V., and Wolf, H. (1967). Postnatal changes in the blood serum content of glycerol and free fatty acids in premature infants. Influence of hypothermia and of respiratory distress. Biologia Neonatorum, 11, 50-60.

Persson, B., and Gentz, J. (1966). The pattern of blood lipids, glycerol and ketone bodies during the neonatal period, infancy and childhood. Acta Paediatrica Scandinavica, 55, 353-362.

Pribylová, H., and Novak, L. (1970). Influence of environmental temperature on the energetic and glyceride metabolism of pathological newborns during the first three hours of life. Biologia Neonatorum, 15, 315-328.

Smales, O. R. C. (1978). Simple method for measuring oxygen consumption in babies. Archives of Disease in Childhood, 53, 53-57.

Correspondence to Professor D. Hull, Department of Child Health, University Hospital and Medical School, Clifton Boulevard, Nottingham NG7 2UH. 